\title{
Cervical cancer risk factors among HIV-infected Nigerian women
}

\author{
Uzoma Ononogbu' ${ }^{1}$, Maryam Almujtaba ${ }^{2}$, Fatima Modibbo ${ }^{3}$, Ishak Lawal ${ }^{4}$, Richard Offiong ${ }^{4}$, Olayinka Olaniyan ${ }^{3}$, \\ Patrick Dakum², Donna Spiegelman ${ }^{1,5}$, William Blattner ${ }^{6}$ and Clement Adebamowo $2,6^{*}$
}

\begin{abstract}
Background: Cervical cancer is the third most common cancer among women worldwide, and in Nigeria it is the second most common female cancer. Cervical cancer is an AIDS-defining cancer; however, HIV only marginally increases the risk of cervical pre-cancer and cancer. In this study, we examine the risk factors for cervical pre-cancer and cancer among HIV-positive women screened for cervical cancer at two medical institutions in Abuja, Nigeria.

Methods: A total of 2,501 HIV-positive women participating in the cervical cancer screen-and-treat program in Abuja, Nigeria consented to this study and provided socio-demographic and clinical information. Log-binomial models were used to calculate relative risk (RR) and $95 \%$ confidence intervals $(95 \% \mathrm{Cl})$ for the risk factors of cervical pre-cancer and cancer.

Results: There was a $6 \%$ prevalence of cervical pre-cancer and cancer in the study population of HIV-positive women. The risk of screening positivity or invasive cancer diagnosis reduced with increasing age, with women aged 40 years and older having the lowest risk $(R R=0.4 ; 95 \% \mathrm{Cl}=0.2-0.7)$. Women with a $C D 4$ count of 650 per $\mathrm{mm}^{3}$ or more also had lower risk of screening positivity or invasive cancer diagnosis ( $R R=0.3,95 \% \mathrm{Cl}=0.2-0.6)$. Other factors such as having had 5 or more abortions $(R R=1.8,95 \% \mathrm{Cl}=1.0-3.6)$ and the presence of other vaginal wall abnormalities ( $\mathrm{RR}=1.9,95 \% \mathrm{Cl}=1.3-2.8)$ were associated with screening positivity or invasive cancer diagnosis.

Conclusion: The prevalence of screening positive lesions or cervical cancer was lower than most previous reports from Africa. HIV-positive Nigerian women were at a marginally increased risk of cervical pre-cancer and cancer. These findings highlight the need for more epidemiological studies of cervical cancer and pre-cancerous lesions among HIV-positive women in Africa and an improved understanding of incidence and risk factors.
\end{abstract}

Keywords: Cervical cancer, Screen and treat, HIV, VIANILI

\section{Background}

In 2008, cervical cancer was the third most common cancer among women and the seventh most common cancer overall with 530,000 new cases and 275,000 deaths reported [1]. Women in Sub-Saharan Africa are disproportionately affected, where it is the most common cancer in women, accounting for $13 \%$ of all female cancers [1,2]. In Nigeria, it is the second most common female cancer after breast cancer, with an age standardized incidence rate of 34.5 cases per 100,000 women in 2010 [3].

\footnotetext{
* Correspondence: cadebamowo@som.umaryland.edu

${ }^{2}$ Office of Research and Training, Institute of Human Virology, Abuja, Nigeria

${ }^{6}$ Department of Epidemiology and Public Health, Institute of Human Virology and Greenebaum Cancer Centre, University of Maryland School of Medicine, Baltimore, MD 21201, USA

Full list of author information is available at the end of the article
}

Virtually all cases of cervical pre-cancer and cancer are associated with a high-risk human papillomavirus (hrHPV) infection, with types 16 and 18 reported to account for the majority of cases $[4,5]$. However, only about $12 \%$ of individuals with persistent hrHPV infection go on to develop cervical pre-cancer and cancer. Hence, hrHPV infection can a cause of cervical cancer, but is not the exclusive cause. In addition to hrHPV, other factors impact progression, from persistent hrHPV infection to cervical pre-cancer to cancer. These include smoking, parity, education, diet, physical inactivity, sexual behavior and use of oral contraceptives [6,7]. Other factors, including population growth and aging, are also contributing to the rising burden of cervical cancer in developing countries [8].

\section{Biomed Central}


Since the onset of the HIV epidemic, the United States Centers for Disease Control and Prevention (CDC) has classified cervical cancer, Kaposi sarcoma and nonHodgkin's lymphoma as AIDS-defining cancers because of their close association with HIV infection [2]. However, unlike the latter two types of cancer, the risk of cervical cancer is only marginally elevated at best among HIV-infected women [9-13]. Furthermore, compared with other AIDS-defining cancers, the incidence of cervical cancer has not decreased substantially with increasing use of anti-retroviral therapy, which suggests that the role of immunosuppression in the progression to invasive cancer may be marginal $[9,14-18]$.

In developed countries, some $75 \%$ of women are screened-typically by Papanicolaou staining (Pap smears) and more recently by human papillomavirus (HPV) DNAbased tests-compared with $5 \%$ in developing countries [19]. As a consequence, the incidence of cervical cancer in developed countries has been reduced substantially, in contrast to developing countries such as Nigeria, where the incidence has remained stable $[3,20]$. The choice of screening method for cervical cancer is also a challenge for developing countries. Widespread adoption of Pap smears has not been feasible in developing countries because of the need for high quality cytology equipment, laboratories and well-trained clinicians who can interpret Pap smear results, the need for multiple hospital visits, and the need for follow-ups and the recall of patients several times $[19,21]$. HPV DNA testing is expensive, requires multiple visits and is beyond the resources of most low- and middle-income countries (LMIC) at the present time. Other factors, including poor health care infrastructure, lack of resources and competing needs for limited health care resources, also mitigate against widespread adoption of cervical cancer screening in low resource countries [19].

An alternative cervical cancer screening method that is recommended for use in developing countries is visual inspection with acetic acid or Lugol's iodine (VIA/VILI). VIA/VILI is an inexpensive test that can be easily adopted and scaled up in the healthcare system of LMIC, does not require specialized laboratories or equipment, can be performed by a wide range of health care professionals after a short period of training and does not require several visits by patients $[10,16,19,22]$. VIA/VILI is increasingly used as a "screen and treat" approach to cervical cancer screening in LMIC where treatment for abnormal lesions is performed during one single clinic visit, thereby minimizing the need of patients having to attend a follow-up $[16,19]$.

In some countries, donor funding from the President's Emergency Plan for AIDS Relief (PEPFAR) and the Global Fund has provided the resources and infrastructure needed to scale up visual inspection with acetic acid testing (VIA) [16]. For example, Zambia leveraged these resources, rapidly expanded its VIA model and integrated it into the health care system. This has ensured the success of the program without placing extra burden on the health care system, thus maximizing the potential of the "screen and treat" approach [10,16,22]. VIA is reported to have $80 \%$ sensitivity, $92 \%$ specificity, a $10 \%$ positive predictive value and a $99 \%$ negative predictive value [21]. In this paper, we report risk factors for VIA/ VILI positivity among the study's screened population in Nigeria.

\section{Methods \\ Place of study}

This study was carried out at the University of Abuja Teaching Hospital and the National Hospital, both in Abuja, Nigeria.

\section{Screening population}

HIV-positive women older than 18 years of age either on anti-retroviral therapy (ART) or ART naïve attending PEPFAR treatment clinics for HIV care were enrolled at both sites. Participants were women who voluntarily presented and gave informed consent for cervical cancer screening.

\section{Screening procedure}

After obtaining informed consent, nurses obtained demographic and clinical information on all participants and examined the introitus and vulva, noting any abnormalities. A bivalve speculum was then introduced into the vagina for examination of the cervix using a halogen lamp. The squamo-columnar junction of the cervix (transformation zone) was identified and any secretions or exudate cleaned off before a nurse applied a cotton wool swab soaked in 5\% acetic acid solution for $3 \mathrm{mi}-$ nutes. The results of each examination were noted. Pre-cancerous lesions were defined as being dense aceto-white lesions with well-defined margins observed within the vicinity of the transformation zone originating from the squamo-columnar junction, or if the whole cervix or cervical growth turned white. A suspicion of cancer was defined as any cervical ulcer or growth being observed [23]. Following VIA, if there was any uncertainty about the lesion observed, visual inspection with Lugol's iodine (VILI) was conducted. A positive VILI was characterized as being well-defined, bright yellow iodine non-uptake areas touching the squamo-columnar junction or close to the cervical os if the squamo-columnar junction was not seen.

Results of VIA or VILI were classified according to the International Agency for Research Against Cancer (IARC) manual and recorded after each test [24]. Positive areas were mapped on case report forms and the 
number of positive lesions, the quadrant affected and degree of extension noted. Digital images (cervigrams) of the cervix were captured for all screened women regardless of the outcome of VIA using off-the-shelf digital cameras (Canon Powershot SX20 IS ${ }^{\circ}$ ). Cervigrams were used to provide patients with immediate feedback on the results of their examination, and were saved on a computer as part of the client's record. They were subsequently reviewed by a consulting gynecologist for quality assurance purposes.

Women with confirmed VIA or VILI positive results were offered immediate treatment with cold coagulation. This is an ablative therapy used for treatment of intraepithelial neoplasia that is not suspected of being cancerous, not covering more than $75 \%$ of the cervix, is not disappearing into the endo-cervical canal, and the squamo-columnar junction is fully visible. A patient with a cervix suspicious for cancer or with intraepithelial neoplasia was ineligible for cold coagulation according to predefined criteria. These women were referred to the gynecology clinic to undergo colposcopy and biopsy to confirm probable cancer diagnosis and to receive further treatment, as is standard practice in screen and treat programs [23].

\section{Quality assurance}

At the end of every week, quality assurance meetings were held with nurses and the consulting gynecologist to review all cervigrams taken during the week, with the aim of assessing the nurses' visual detection skills and referral decisions. In those cases where there was a missed diagnosis of clinical relevance the patient was recalled.

\section{Statistical analysis}

Relative risk and $95 \%$ confidence intervals $(95 \% \mathrm{CI})$ were calculated using log-binomial regression models [25,26]. The $\mathrm{p}$-value for trend for ordinal variables was calculated using the median value of each category. A liberal criterion for the selection of potential confounders and possible independent risk factors was employed; all variables that were significant in the univariate models at $p \leq 0.20$ were included in the multivariate models [27]. We divided the continuous variables (age and last CD4 count) by multiples of five, which corresponded approximately to quartiles of the age distribution. We investigated possible non-linearity in the log-binomial models between screening status and continuous variables (age, age at first sexual intercourse, total number of pregnancies, total number of abortions and last CD4 count) using stepwise restricted cubic splines. A likelihood ratio test was used to compare the log-linear model to the model with any nonlinear terms that were selected in the smoothing process $[28,29]$. All data analysis was performed using SAS 9.3 (SAS Institute; Cary, NC, USA).

\section{Results}

Socio-demographic and clinical characteristics of the study participants are shown in Tables 1 and 2. A total of 2,501 HIV-infected women on ART were screened between 2010 and 2012. The mean age and standard deviation (SD; the second number) was 35 (7) years. The mean number of sexual partners (SD) was 1 (1). The mean age (SD) at first sexual intercourse was 19 (4) years. The mean (SD) number of pregnancies was 4 (2). The mean (SD) number of abortions experienced was 2 (2). Christianity was the most common religion, with $84 \%$ of the women identifying as Christians. The level of education within this group of women was high, with $77 \%$ having secondary education or higher. The majority of women, $52 \%$, were married at the time of the study. Most women, 77\%, had CD4 counts above 300; the median CD4 count was 451 cells per $\mathrm{mm}^{3}$. The majority of the HIV-infected women, $86 \%$, were asymptomatic and were classified as having Stage 1 at baseline as defined by World Health Organization guidelines [30].

Few participants, 6\%, had a positive screening test result or a confirmed diagnosis of invasive cervical cancer. Women with positive results and invasive cancer were grouped together for analysis; although we recognize that a positive VIA/VILI result does not necessarily equate to a cervical cancer diagnosis. The results of the univariate associations are shown in Table 3. The median age of women with a positive screening result/invasive cancer was 32 years compared with a median of 35 years in women with a negative screening result ( $\mathrm{p}_{\text {trend }}<$ 0.0001 ). The median number of pregnancies among women with a positive VIA result/invasive cancer was 3 compared with 4 pregnancies in women with a negative $\left(\mathrm{p}_{\text {trend }}=0.03\right)$. A greater proportion of women with VIA positive lesions were Christians $(\mathrm{p}=0.04)$. Women with a positive screening result/invasive cancer also had a higher proportion of vaginal wall abnormality $(\mathrm{p}=0.0006)$. The most recent CD4 count prior to screening was significantly higher among women with a negative screening result compared with women with a positive screening result/invasive cancer $(\mathrm{p}<0.0001)$. The results of the multivariate analyses are shown in Table 3. The risk of screening positivity or invasive cancer diagnosis decreased with increasing age, with women aged 40 years and older having the lowest risk ( $R R=0.4 ; 95 \%$ $\mathrm{CI}=0.2-0.7$ ). Women with a CD4 count of 650 per $\mathrm{mm}^{3}$ or more had the lowest risk of screening positivity or invasive cancer diagnosis $(\mathrm{RR}=0.3,95 \% \mathrm{CI}=0.2-0.6)$. Other independent risk factors, such as having had five or more abortions $(\mathrm{RR}=1.8,95 \% \mathrm{CI}=1.0-3.6)$ and the presence of other vaginal wall abnormalities ( $\mathrm{RR}=1.9,95 \% \mathrm{CI}=1.3-2.8)$, were associated with screening positivity or invasive cancer diagnosis. There were no independent associations with age at first sexual intercourse or multiple 
Table 1 Socio-demographic characteristics of HIV-infected women $(n=2,501)$

\begin{tabular}{|c|c|c|}
\hline & n (\%) & Missing (\%) \\
\hline Age category (years) & & $11(0.4)$ \\
\hline$<30$ & $504(20)$ & \\
\hline $30-34$ & $696(28)$ & \\
\hline $35-39$ & $663(27)$ & \\
\hline$\geq 40$ & $627(25)$ & \\
\hline Age at first sexual intercourse (years) & & $29(1.2)$ \\
\hline$<15$ & $156(6)$ & \\
\hline $15-19$ & $1242(50)$ & \\
\hline $20-24$ & $856(35)$ & \\
\hline$\geq 25$ & $218(9)$ & \\
\hline Number of sexual partners & & $10(0.4)$ \\
\hline$\leq 2$ & $2400(96)$ & \\
\hline $3-4$ & $68(3)$ & \\
\hline$\geq 5$ & $23(1)$ & \\
\hline Total number of pregnancies $^{1}$ & & $1(0.04)$ \\
\hline $0-2$ & $722(29)$ & \\
\hline $3-4$ & $827(33)$ & \\
\hline $5-6$ & $571(23)$ & \\
\hline$\geq 7$ & $380(15)$ & \\
\hline Total number of abortions & & $6(0.2)$ \\
\hline $0-2$ & $1873(75)$ & \\
\hline $3-4$ & $445(18)$ & \\
\hline$\geq 5$ & $177(7)$ & \\
\hline Religion & & $5(0.2)$ \\
\hline Islam & $404(16)$ & \\
\hline Christian & $2092(84)$ & \\
\hline Education & & $2(0.1)$ \\
\hline None & $150(6)$ & \\
\hline Quaranic & $27(1)$ & \\
\hline Primary & $402(16)$ & \\
\hline Secondary & $773(31)$ & \\
\hline Tertiary & $1147(46)$ & \\
\hline Marital Status & & $0(0)$ \\
\hline Single & $443(18)$ & \\
\hline Married & $1297(52)$ & \\
\hline Widowed & $537(21)$ & \\
\hline Divorced & $207(8)$ & \\
\hline Cohabiting & $17(1)$ & \\
\hline Contraceptives use ${ }^{2}$ & & $3(0.1)$ \\
\hline Yes & $657(26)$ & \\
\hline No & $1841(74)$ & \\
\hline Hormonal contraceptives $^{3}$ & & $0(0)$ \\
\hline Yes & $29(1)$ & \\
\hline No & 2472 (99) & \\
\hline
\end{tabular}

Table 1 Socio-demographic characteristics of HIV-infected women ( $\mathbf{n = 2 , 5 0 1 )}$ (Continued)

\begin{tabular}{lll}
\hline Intrauterine devices & $1(0.04)$ \\
\hline Yes & $32(1)$ & \\
\hline No & & $2468(99)$ \\
\hline Barrier contraceptives & $0(0)$ \\
\hline Yes & $554(22)$ & \\
\hline No & $1947(78)$ & \\
\hline Tubal ligation & & \\
\hline Yes & $11(0.04)$ \\
\hline No & $2489(100)$ & \\
\hline
\end{tabular}

${ }^{1}$ Total number of pregnancies is defined as pregnancies carried after 28-weeks, regardless of outcome.

${ }^{2}$ Contraceptive use refers to history of contraceptive use.

${ }^{3}$ Hormonal contraceptives includes oral contraceptives, hormonal injections and intradermal implants.

pregnancies. We detected non-linearity in the relationship between age and screening status, where risk was slightly elevated up to age 35 and then declined dramatically up to age 50, after which no further decrease in risk was apparent (Figure 1).

\section{Discussion}

In this study of cervical cancer risk factors in HIVpositive Nigerian women, we found a $6 \%$ prevalence of cervical pre-cancer and cancer. This finding is inconsistent with previous reports from other Sub-Saharan African countries where a higher prevalence of pre-cancer and cancer has been reported [31-38]. Studies conducted in Rwanda, Kenya, South Africa, Uganda and Zambia reported prevalence of cervical pre-cancer and cancer among HIV-positive women of $24.3 \%, 26.7 \%, 66.3 \%$, $73.0 \%$ and $76 \%$, respectively [31-35].

In order to address these inconsistencies, knowing that the age-standardized incidence of cervical cancer in Nigeria is 34.5 per 100,000 people/year and this has not changed significantly in the last few decades [3], that $20 \%$ of cervical abnormalities if untreated progress to carcinoma, and assuming that the average duration from a cervical abnormality to cancer is about 15 years given that the average duration of cervical cancer from the time of infection with the HPV to cervical cancer has been estimated at 30 years [39], it is possible to estimate the expected prevalence of cervical abnormalities. The relationship between the incidence, I, and the point prevalence of disease, $\mathrm{p}$, can be used to calculate the expected prevalence of cervical abnormalities as follows: $p=\frac{I \bar{D}}{1+I D}$, where $\bar{D}$ is the average duration of the disease [40]. Applying this formula and based on the assumptions made above, an expected prevalence of $2.5 \%$ is obtained. Further assumptions based on the sensitivity of VIA/VILI will increase this prevalence estimate. It is 
Table 2 Clinical characteristics of HIV-infected women $(n=2,501)$

\begin{tabular}{|c|c|c|}
\hline & n (\%) & Missing (\%) \\
\hline BMI $\left(\mathrm{kg} / \mathrm{m}^{2}\right)$ & & $1840(73.6)$ \\
\hline$<18.5$ & $46(7)$ & \\
\hline $18.5-24.9$ & $401(61)$ & \\
\hline $25-29.9$ & $49(7)$ & \\
\hline$\geq 30$ & $165(25)$ & \\
\hline Vaginal wall abnormality & & $0(0)$ \\
\hline None & $2241(90)$ & \\
\hline Other $^{1}$ & $260(10)$ & \\
\hline VIA & & $0(0)$ \\
\hline Negative & $2344(94)$ & \\
\hline Positive & $155(6)$ & \\
\hline Invasive cancer & $2(0)$ & \\
\hline Last CD4 count (per $\mathrm{mm}^{3}$ ) & & $365(14.6)$ \\
\hline$<300$ & $490(23)$ & \\
\hline $300-<450$ & $560(26)$ & \\
\hline $450-<650$ & $592(28)$ & \\
\hline$\geq 650$ & $494(23)$ & \\
\hline WHO stage & & $1118(44.7)$ \\
\hline Stage 1 & $1185(86)$ & \\
\hline Stage 2 & $104(7)$ & \\
\hline Stage 3 & $84(6)$ & \\
\hline Stage 4 & $10(1)$ & \\
\hline ART regimen currently on ${ }^{2}$ & & $1008(40)$ \\
\hline TDF-containing $\mathrm{ART}^{3}$ & $778(52)$ & \\
\hline ZDV-containing $\mathrm{ART}^{4}$ & $600(40)$ & \\
\hline $\mathrm{d} 4 \mathrm{~T}$-containing $\mathrm{ART}^{5}$ & $115(8)$ & \\
\hline
\end{tabular}

'Other includes discharge, lesion, warts, lesion and warts, warts and discharge, and other observations.

${ }^{2} \mathrm{All}$ women were on ART, the regimen information here is based on those that were verified from clinical records.

${ }^{3}$ TDF: Tenofovir.

${ }^{4}$ ZDV: Zidovudine.

${ }^{5} \mathrm{~d} 4 \mathrm{~T}$ : Stavudine.

also easy to see how, with small departures from these assumptions, the prevalence of cervical abnormality observed in the study could have been easily obtained. For example, if only $10 \%$ of untreated cervical abnormalities in this setting progress to frank cancer, the expected prevalence of cervical abnormalities would be $4.9 \%$. It is noted that the incidence of cervical cancer in East Africa is about $50 \%$ higher than in West Africa [1]. For prevalence to be as high as that reported in some of the other studies in Sub-Saharan African, such as $27 \%$ as reported in a recent study among HIV-infected women in Kenya, the cervical cancer incidence rate would have to be about 493/100,000 people/year; approximately 10 -fold greater than what has been observed in African population-based registries. Thus, it is probable that the cervical pre-cancer and cancer prevalence obtained in these other studies were over-estimated and the results of the present study are likely to be much closer to the true value.

The higher prevalence reported by some of these other studies may also be partly explained by differences in the sexual practices of the women studied [2]. Having multiple sexual partners increases the risk of acquiring HPV, and in turn, the development of cervical pre-cancer and cancer. In Cote D'Ivoire, $56 \%$ of the women had $\geq 5$ lifetime sexual partners and in South Africa the median number of sexual partners was 4 , while in the present study $96 \%$ of women reported $\leq 2$ sexual partners $[2,33,41]$. It is, however, unlikely that these differences are sufficient to account for such high rates of prevalence as those reported in some of the previous studies. The limitations of self-reported sexual practices data are noted, but it is not believed that this would differ systematically among Sub-Saharan countries [42].

This study is similar to other studies where participants are recruited through HIV and ART clinics [5,32,33,43]. The median age of women in this study was similar to that of women in other studies [32,33,44]. In general, women in the current study had higher CD4 counts than women in other studies, as all HIV-infected women in this study had initiated ART treatment $[32,33,44]$.

The prevalence and incidence of cervical cancer is only marginally affected by HIV/AIDS [2]. Since the introduction of anti-retroviral therapy, the incidence of cervical cancer has not decreased substantially, unlike that of other AIDS-defining cancers such as Kaposi's sarcoma and non-Hodgkin's lymphoma. This suggests that immunosuppression caused by HIV infection is only marginally associated, at best, with the progression to cervical cancer [9,14-18]. The lack of a decrease in the incidence of cervical cancer in this era of effective ART is supported by data from HIV/AIDS cohorts in developed countries $[18,45,46]$. This finding may be partially explained by the lack of impact of immunosuppression on carcinogenetic HPV, a necessary but not sufficient cause of cervical pre-cancer and cancer $[44,47]$.

The majority of the women in this study were aged between 30 and 39 (55\%), and the median age observed for an invasive cancer diagnosis or positive screening result was 32 years, which is about 10 years younger than the median age of 47 years for cervical cancer diagnosis in the general population [48]. This result is similar to that of other studies from Africa, which showed HIV-positive women presenting with cervical pre-cancer and cancer at an earlier age. In Kenya and South Africa, HIVpositive women with invasive cervical cancer were on average about 10 years younger compared with women who were HIV-negative [49,50]. One hypothesis is that unsafe sexual behavior puts women at risk of both HPV 
Table 3 Association between socio-demographic and clinical characteristics and a positive cervical screening test among HIV-infected women

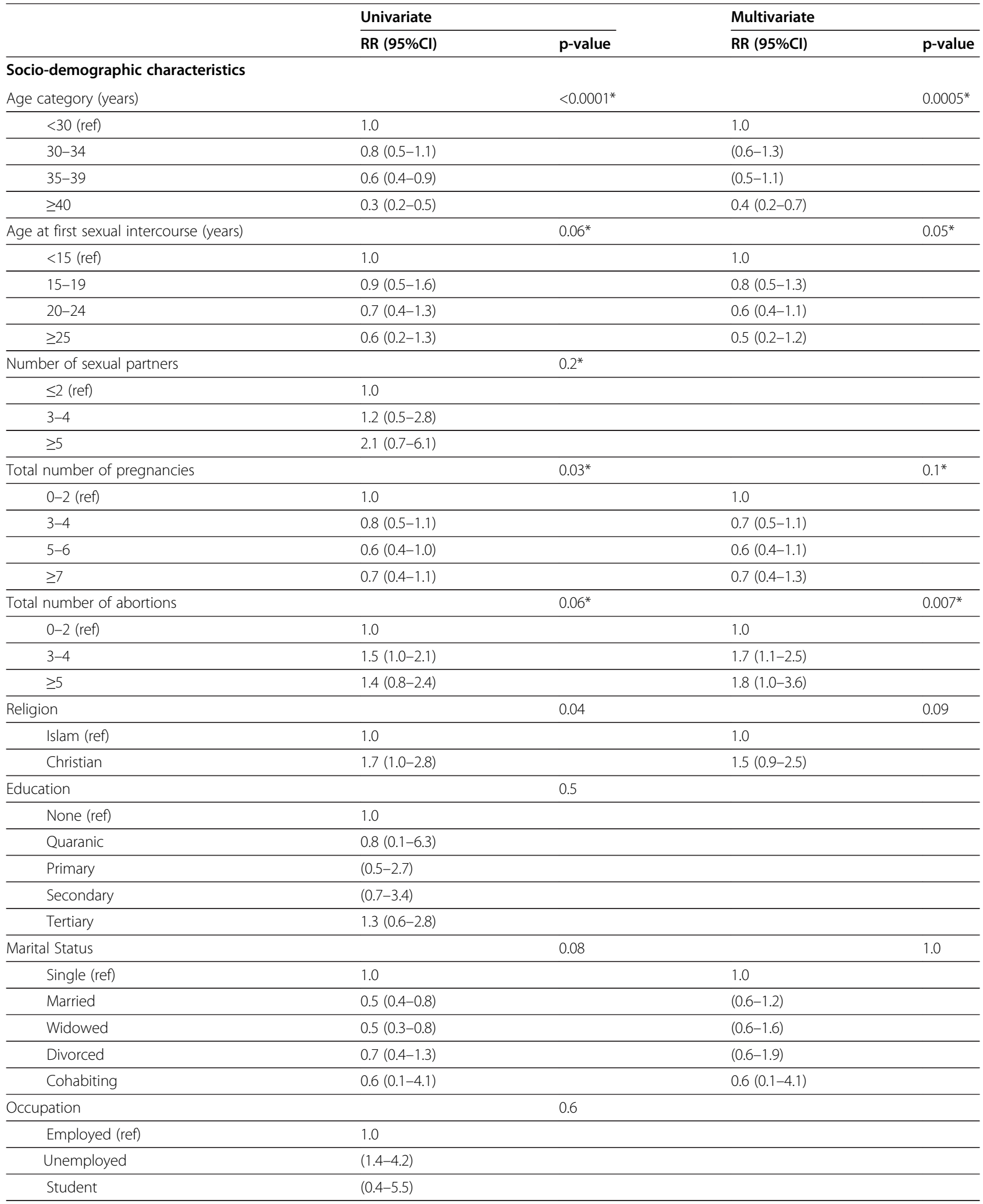


Table 3 Association between socio-demographic and clinical characteristics and a positive cervical screening test among HIV-infected women (Continued)

\begin{tabular}{|c|c|c|c|c|}
\hline Other & $1.0(0.5-2.1)$ & & & \\
\hline N/A & $1.4(0.4-5.3)$ & & & \\
\hline Contraceptive use & $1.0(0.7-1.4)$ & 1.0 & & \\
\hline $\begin{array}{l}\text { Hormonal } \\
\text { contraceptives }\end{array}$ & $0.6(0.1-3.8)$ & 0.5 & & \\
\hline Intrauterine devices & $1.5(0.5-4.5)$ & 0.5 & & \\
\hline Barrier contraceptives & $1.2(0.8-1.7)$ & 0.4 & & \\
\hline \multicolumn{5}{|l|}{ Clinical characteristics } \\
\hline BMI $\left(\mathrm{kg} / \mathrm{m}^{2}\right)$ & & 0.8 & & \\
\hline$<18.5$ (ref) & 1.0 & & & \\
\hline $18.5-24.9$ & $(0.7-1.5)$ & & & \\
\hline $25-29.9$ & $0.6(0.2-2.5)$ & & & \\
\hline$\geq 30$ & $1.0(0.5-1.8)$ & & & \\
\hline Vaginal wall abnormality & & 0.0006 & & 0.0007 \\
\hline None (ref) & 1.0 & & 1.0 & \\
\hline Other & $2.0(1.3-2.9)$ & & $1.9(1.3-2.8)$ & \\
\hline Last CD4 count (per $\mathrm{mm}^{3}$ ) & & $<0.0001^{*}$ & & $<0.0001^{*}$ \\
\hline$<300$ (ref) & 1.0 & & 1.0 & \\
\hline $300-<450$ & $0.5(0.3-0.7)$ & & $(0.3-0.7)$ & \\
\hline $450-<650$ & $0.5(0.3-0.7)$ & & $0.5(0.3-0.8)$ & \\
\hline$\geq 650$ & $0.3(0.2-0.5)$ & & $0.3(0.2-0.6)$ & \\
\hline WHO stage & & 1.0 & & \\
\hline Stage 1 (ref) & 1.0 & & & \\
\hline Stage 2 & $(0.2-1.4)$ & & & \\
\hline Stage 3 & $1.3(0.6-2.7)$ & & & \\
\hline Stage 4 & $1.6(0.2-10.2)$ & & & \\
\hline ART Regimen currently on & & 0.6 & & \\
\hline TDF-containing ART & $1.4(1.0-2.0)$ & & & \\
\hline ZDV-containing ART & $(1.0-2.2)$ & & & \\
\hline d4T-containing ART & $0.9(0.4-2.1)$ & & & \\
\hline
\end{tabular}

${ }^{*} \mathrm{p}$-value for trend using median value of each category.

and HIV, and that this may explain the younger age of presentation of HIV-infected women [49]. However, given the results from HIV cohorts in developed countries that suggest a limited role of HIV-associated immunosuppression in cervical carcinogenesis $[18,45,46]$, the differences in age between HIV-positive and HIVnegative people may be a reflection of the lower life expectancy of persons living with HIV/AIDS in Africa.

The results of this study suggest that HIV-infected women with higher CD4 cell counts were at a reduced risk for invasive cancer diagnosis or a positive VIA result. This result agrees with findings from other studies. For example, in Rwanda, an inverse association was found between the CD4 count and cervical pre-cancer among HIV-infected women [44]. Harris et al. found that HIV-negative and HIV-positive women with a CD4 cell count of greater than 500 cells per $\mathrm{mm}^{3}$ had low incidence of cervical pre-cancer compared with those with lower CD4 counts [51]. These findings may reflect competing risks in HIV-positive patients with low CD4 counts, and the need to focus more on immune reconstitution in that population. It also appears that once pre-cancerous lesions develop, disease progression is not affected by the CD4 count, consistent with the marginal role previously reported for immunosuppression in disease progression [52].

We also found the risk for cervical pre-cancer and cancer to be associated with age ( $\geq 40$ years) which supports the natural history of cervical carcinogenesis from hrHPV infection through cervical dysplasia, pre-cancer and cancer; having five or more abortions and the presence of vaginal wall abnormalities suggesting a generalized increased risk of sexually transmitted diseases in women who have cervical pre-cancer and cancer. The 


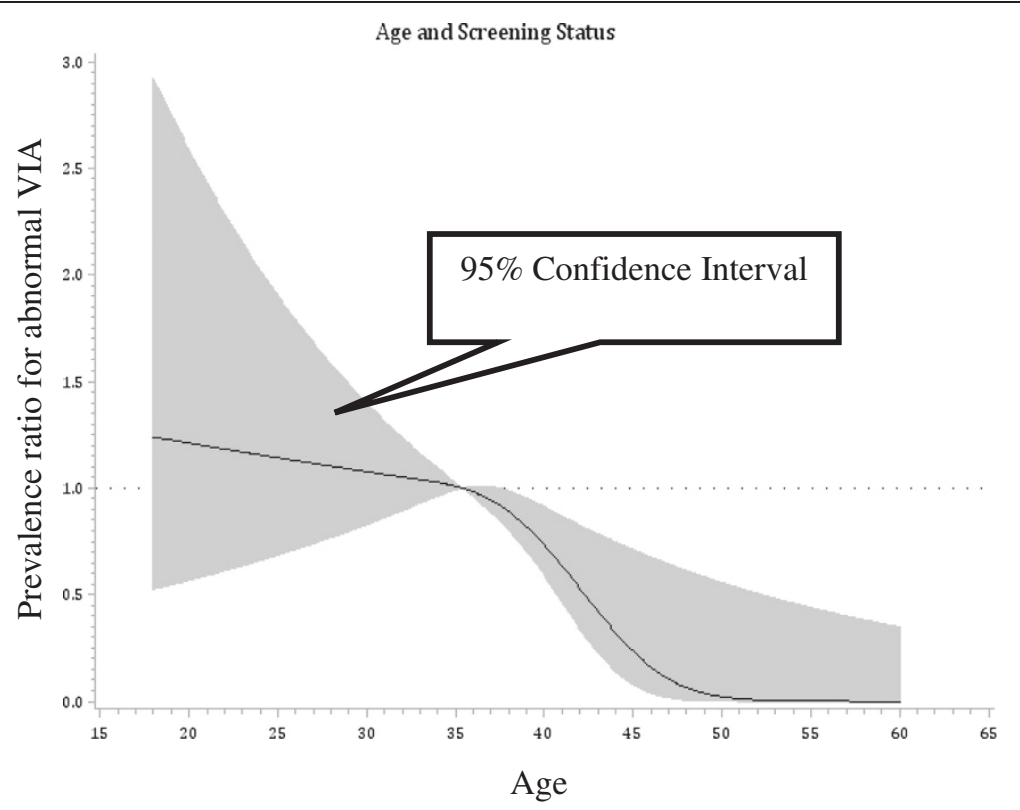

Figure 1 Relationship between age and screening status of HIV-infected women participating in cervical cancer screening in Abuja, Nigeria 2012.

non-linearity in the relationship between age and screening status may be due to the natural history of cervical carcinogenesis where infection needs to persist before engendering malignant change [53].

As this was a cross-sectional study it was not possible to explore cause-and-effect relationships. We did not perform HPV DNA testing, cytology or biopsies to confirm the result of visual inspections; as a result, visually inapparent pre-cancerous lesions could have been missed. Also, since this study was conducted among HIV-infected women on ART, the results may not be generalizable to uninfected women. Nevertheless, we believe this study demonstrates the risk factors of positive cervical cancer screening test in this population.

\section{Conclusion}

In conclusion, HIV-positive Nigerian women are at a marginally increased risk for cervical pre-cancer and cancer. Our study highlight the importance of screening HIV-positive women in Nigeria for cervical cancer. The screen and treat approach using VIA/VILI has been shown to be effective for the detection of cervical precancer and cancer, and incorporation of immediate treatment where applicable is associated with reduced loss to follow-up. This can also be rapidly scaled up in resourceconstrained settings and be incorporated into HIV treatment programs. Our results demonstrate the need for more epidemiological studies of cervical pre-cancer and cancer among HIV-positive, indeed all women in Africa and an improved understanding of incidence and risk factors.

\section{Consent}

Written informed consent was obtained from the patient for publication of this report and any accompanying images.

\section{Competing interests}

The authors declare that they have no competing interests.

\section{Authors' contributions}

$\cup O$ conducted the data analysis and drafted the manuscript. MA implemented the study, collected data, assisted with data analysis and drafting of the manuscript. ZM implemented the study, collected data, assisted with data analysis and drafting of the manuscript. IL worked on study implementation and data collection. RO supervised clinical data collection and assisted with drafting the manuscript. OO supervised clinical data collection and assisted with drafting the manuscript. PD supervised clinical data collection and assisted with drafting the manuscript. DS supervised data analysis and writing of the manuscript. WB supervised clinical data collection and assisted with drafting the manuscript. CA conceived the study, participated in study implementation, data collection, data analysis and drafting of the manuscript. All authors read and approved the final manuscript.

\section{Acknowledgments}

This work was supported by the UM-Capacity Development for Research in AIDS Associated Malignancy Grant (D43CA153792) from the National Cancer Institute and IHV-UM AIDS International Training and Research Program (D43TW001041) from the Fogarty International Center. The content of this paper is solely the responsibility of the authors and does not necessarily represent the official views of the National Cancer Institute or the National Institutes of Health.

\section{Author details}

${ }^{1}$ Department of Epidemiology, Harvard School of Public Health, Boston, MA 02115, USA. ${ }^{2}$ Office of Research and Training, Institute of Human Virology, Abuja, Nigeria. ${ }^{3}$ National Hospital, Abuja, Nigeria. ${ }^{4}$ University of Abuja Teaching Hospital, Gwagwalada, Nigeria. ${ }^{5}$ Department of Biostatistics, Harvard School of Public Health, Boston, MA 02115, USA. 'Department of Epidemiology and Public Health, Institute of Human Virology and 
Greenebaum Cancer Centre, University of Maryland School of Medicine, Baltimore, MD 21201, USA.

Received: 12 January 2013 Accepted: 5 June 2013 Published: 14 June 2013

\section{References}

1. Ferlay J, Shin HR, Bray F, Forman D, Mathers C, Parkin DM: GLOBOCAN 2008 v1.2, Cancer Incidence and Mortality Worldwide: IARC Cancer Base No. 10 [Internet]. Lyon, France: International Agency for Research on Cancer; 2010.

2. Mbulaiteye SM, Bhatia K, Adebamowo C, Sasco AJ: HIV and cancer in Africa: mutual collaboration between HIV and cancer programs may provide timely research and public health data. Infectious Agents and Cancer 2011, 6(1):16.

3. Jedy-Agba E, Curado MP, Ogunbiyi O, Oga E, Fabowale T, Igbinoba F, Osubor G, Otu T, Kumai H, Koechlin A: Cancer incidence in Nigeria: A report from population-based cancer registries. Cancer Epidemiology 2012, 36(5):e271-e278

4. Clifford GM, Smith JS, Plummer M, Munoz N, Franceschi S: Human papillomavirus types in invasive cervical cancer worldwide: a metaanalysis. $\mathrm{Br} J$ Cancer 2003, 88(1):63-73.

5. Vuyst HD, Ndirangu G, Moodley M, Tenet V, Estambale B, Meijer CJ, Snijder PJ, Clifford G, Franceschi S: Prevalence of human papillomavirus in women with invasive cervical carcinoma by HIV status in Kenya and South Africa. International journal of cancer Journal international du cancer 2012, 131(4):949-955.

6. Castellsague X, Diaz M, de Sanjose S, Munoz N, Herrero R, Franceschi S, Peeling RW, Ashley R, Smith JS, Snijders PJ, et al: Worldwide human papillomavirus etiology of cervical adenocarcinoma and its cofactors: implications for screening and prevention. J Nat/ Cancer Inst 2006, 98(5):303-315.

7. Castellsague $X$, Munoz N: Chapter 3: Cofactors in human papillomavirus carcinogenesis--role of parity, oral contraceptives, and tobacco smoking. Journal of the National Cancer Institute Monographs 2003, 31(31):20-28.

8. Thun MJ, DeLancey JO, Center MM, Jemal A, Ward EM: The global burden of cancer: priorities for prevention. Carcinogenesis 2010, 31(1):100-110

9. Frisch M, Biggar RJ, Goedert JJ: Human papillomavirus-associated cancers in patients with human immunodeficiency virus infection and acquired immunodeficiency syndrome. J Nat/ Cancer Inst 2000, 92(18):1500-1510.

10. Parham G: Cervical cancer prevention in HIV-infected women in resource-limited settings. HIV Therapy 2010, 4(6):625-628.

11. De Vuyst H, Lillo F, Broutet N, Smith JS: HIV, human papillomavirus, and cervical neoplasia and cancer in the era of highly active antiretroviral therapy. Eur J Cancer Prev 2008, 17(6):545-554

12. Ellerbrock TV, Chiasson MA, Bush TJ, Sun XW, Sawo D, Brudney K, Wright TC $\mathrm{Jr}$ : Incidence of cervical squamous intraepithelial lesions in HIV-infected women. JAMA 2000, 283(8):1031-1037.

13. Ahdieh L, Klein RS, Burk R, Cu-Uvin S, Schuman P, Duerr A, Safaeian M, Astemborski J, Daniel R, Shah K: Prevalence, incidence, and type-specific persistence of human papillomavirus in human immunodeficiency virus (HIV)-positive and HIV-negative women. J Infect Dis 2001, 184(6):682-690.

14. IC HIV, Coutinho RA: Highly active antiretroviral therapy and incidence of cancer in human immunodeficiency virus-infected adults. I Nat/ Cancer Inst 2000, 92(15):1823-1830.

15. Heard I: Prevention of cervical cancer in women with HIV. Curr Opin HIV AIDS 2009, 4(1):68-73.

16. Mwanahamuntu MH, Sahasrabuddhe W, Kapambwe S, Pfaendler KS Chibwesha C, Mkumba G, Mudenda V, Hicks ML, Vermund SH, Stringer JS, et al: Advancing cervical cancer prevention initiatives in resourceconstrained settings: insights from the Cervical Cancer Prevention Program in Zambia. PLoS Med 2011, 8(5):e1001032

17. Biggar RJ, Chaturvedi AK, Goedert JJ, Engels EA: AIDS-related cancer and severity of immunosuppression in persons with AIDS. J Nat/ Cancer Inst 2007, 99(12):962-972.

18. Clifford GM, Polesel J, Rickenbach M, Dal Maso L, Keiser O, Kofler A, Rapiti E, Levi F, Jundt G, Fisch T: Cancer risk in the Swiss HIV Cohort Study: associations with immunodeficiency, smoking, and highly active antiretroviral therapy. J Natl Cancer Inst 2005, 97(6):425-432.

19. Denny L, Quinn M, Sankaranarayanan R: Chapter 8: Screening for cervical cancer in developing countries. Vaccine 2006, 24(3):71-77.

20. Jedy-Agba EE, Curado MP, Oga E, Samaila MO, Ezeome ER, Obiorah C, Erinomo OO, Ekanem IA, Uka C, Mayun A: The role of hospital-based cancer registries in low and middle income countries-The Nigerian Case Study. Cancer Epidemiol 2012, 36(5):430-435.

21. Sauvaget C, Fayette JM, Muwonge R, Wesley R, Sankaranarayanan R: Accuracy of visual inspection with acetic acid for cervical cancer screening. International journal of gynaecology and obstetrics: the official organ of the International Federation of Gynaecology and Obstetrics 2011, 113(1):14-24.

22. Sahasrabuddhe W, Parham GP, Mwanahamuntu MH, Vermund SH: Cervical cancer prevention in low- and middle-income countries: feasible, affordable, essential. Cancer Prev Res (Phila) 2012, 5(1):11-17.

23. IARC: Screening Tests. In Cervix Cancer Screening. Volume 10. Lyon, France: IARC; 2005:59-109.

24. Sankaranarayanan R, Wesley RS: A practical manual on visual screening for cervical neoplasia. Lyon, France: IARC Press; 2003 [IARC Technical Publication No. 41].

25. Spiegelman D, Hertzmark E: Easy SAS calculations for risk or prevalence ratios and differences. Am J Epidemio/ 2005, 162(3):199-200.

26. Wacholder S: Binomial regression in GLIM: estimating risk ratios and risk differences. Am J Epidemiol 1986, 123(1):174-184.

27. Maldonado G, Greenland S: Simulation study of confounder-selection strategies. Am J Epidemiol 1993, 138(11):923-936.

28. Durrleman S, Simon R: Flexible regression models with cubic splines. Stat Med 2006, 8(5):551-561.

29. Govindarajulu US, Spiegelman D, Thurston SW, Ganguli B, Eisen EA: Comparing smoothing techniques in Cox models for exposure-response relationships. Stat Med 2007, 26(20):3735-3752.

30. World Health Organization: Interim WHO clinical staging of HIV/AIDS and HIV AIDS case definitions for surveillance: African region. Geneva, Switzerland: World Health Organization; 2005.

31. Leroy V, Ladner J, De Clercq A, Meheus A, Nyiraziraje M, Karita E, Dabis F: Cervical dysplasia and HIV type 1 infection in African pregnant women: a cross sectional study, Kigali, Rwanda. The Pregnancy and HIV Study Group (EGE). Sex Transm Infect 1999, 75(2):103-106.

32. Memiah P, Mbuthia W, Kiiru G, Agbor S, Odhiambo F, Ojoo S, Biadgilign S: Prevalence and Risk Factors Associated with Precancerous Cervical Cancer Lesions among HIV-Infected Women in Resource-Limited Settings. AIDS research and treatment 2012, 2012:953743.

33. Moodley J, Constant D, Hoffman M, Salimo A, Allan B: Human papillomavirus prevalence, viral load and pre-cancerous lesions of the cervix in women initiating highly active antiretroviral therapy in South Africa: a cross-sectional study. BMC Cancer 2009, 9(1):275.

34. Blossom DB, Beigi RH, Farrell JJ, Mackay W, Oadadri B, Brown DR, Rwambuya S, Walker CJ, Kambugu FS, Abdul-Karim FW: Human papillomavirus genotypes associated with cervical cytologic abnormalities and HIV infection in Ugandan women. J Med Virol 2007, 79(6):758-765.

35. Parham GP, Sahasrabuddhe W, Mwanahamuntu MH, Shepherd BE, Hicks ML, Stringer EM, Vermund SH: Prevalence and predictors of squamous intraepithelial lesions of the cervix in HIV-infected women in Lusaka, Zambia. Gynecol Oncol 2006, 103(3):1017-1022.

36. Hawes SE, Critchlow CW, Niang MAF, Diouf MB, Diop A, Toure P, Kasse AA Dembele B, Sow PS, Coll-Seck AM: Increased risk of high-grade cervical squamous intraepithelial lesions and invasive cervical cancer among African women with human immunodeficiency virus type 1 and 2 infections. J Infect Dis 2003, 188(4):555-563.

37. Keita N, Clifford GM, Koulibaly M, Douno K, Kabba I, Haba M, Sylla BS, Van Kemenade FJ, Snijders PJF, Meijer C: HPV infection in women with and without cervical cancer in Conakry, Guinea. Br J Cancer 2009, 101(1):202-208.

38. Okonda S, Wright C, Michelow P: The status of cervical cytology in Swaziland, Southern Africa: a descriptive study. Cytojournal 2009, 6(1):14

39. Wilbanks GD: Summary of informal discussion on general aspects of cervical cancer. Cancer Res 1973, 33(6):1382-1384.

40. Rothman K, Greenland S: Modern Epidemiology, 2nd edn. Boston, MA Lippincott, Williams and Wilkins; 1998.

41. Horo A, Jaquet A, Ekouevi DK, Toure B, Coffie PA, Effi B, Messou E, Minga A, Moh R, Kone M: Cervical cancer screening by visual inspection in Cote d'Ivoire, operational and clinical aspects according to HIV status. BMC Public Health 2012, 12(1):237.

42. Weinhardt LS, Carey MP, Johnson BT, Bickham NL: Effects of HIV counseling and testing on sexual risk behavior: a meta-analytic review of published research, 1985-1997. Am J Public Health 1999, 89(9):1397-1405

43. Singh DK, Anastos K, Hoover DR, Burk RD, Shi Q, Ngendahayo L, Mutimura E, Cajigas A, Bigirimani V, Cai X, Rwamwejo J, Vuolo M, Cohen M, Castle PE: 
Human Papillomavirus Infection and Cervical Cytology in HIV-Infected and HIV-Uninfected Rwandan Women. J Infect Dis 2009, 199(12):1851-1861.

44. Anastos K, Hoover DR, Burk RD, Cajigas A, Shi Q, Singh DK, Cohen MH, Mutimura E, Sturgis C, Banzhaf WC, Castle PE: Risk factors for cervical precancer and cancer in HIV-infected, HPV-positive Rwandan women. PLoS One 2010, 5(10):e13525.

45. Patel P, Hanson DL, Sullivan PS, Novak RM, Moorman AC, Tong TC, Holmberg SD, Brooks JT: Incidence of types of cancer among HIV-infected persons compared with the general population in the United States, 1992-2003. Ann Intern Med 2008, 148(10):728-736.

46. Dal Maso L, Polesel J, Serraino D, Lise M, Piselli P, Falcini F, Russo A, Intrieri $T$, Vercelli M, Zambon P: Pattern of cancer risk in persons with AIDS in Italy in the HAART era. Br J Cancer 2009, 100(5):840-847.

47. Anderson J, Lu E, Sanghvi H, Kibwana S, Lu A: Cervical cancer screening and prevention for HIV-infected women in the developing world. Mol Biosyst 2010, 6:1162-1172.

48. US Cancer Statistics Working Group: United States Cancer Statistics: 19992007 Incidence and Mortality Web-based Report, US Department of Health and Human Services, Centers for Disease Control and Prevention, and National Cancer Institute. Atlanta GA; 2010.

49. Gichangi PB, Bwayo J, Estambale B, De Vuyst H, Ojwang S, Rogo K, Abwao $\mathrm{H}$, Temmerman M: Impact of HIV infection on invasive cervical cancer in Kenyan women. AIDS 2003, 17(13):1963-1968.

50. Moodley M, Moodley J, Kleinschmidt I: Invasive cervical cancer and human immunodeficiency virus (HIV) infection: a South African perspective. Int J Gynecol Cancer 2001, 11(3):194-197.

51. Harris TG, Burk RD, Palefsky JM, Massad LS, Bang JY, Anastos K, Minkoff H, Hall CB, Bacon MC, Levine AM: Incidence of cervical squamous intraepithelial lesions associated with HIV serostatus, CD4 cell counts, and human papillomavirus test results. JAMA 2005, 293(12):1471-1476,

52. Cardillo M, Hagan R, Abadi J, Abadi MA: CD4 T-Cell count, viral load, and squamous intraepithelial lesions in women infected with the human immunodeficiency virus. Cancer Cytopathol 2001, 93(2):111-114.

53. Schiffman MH, Brinton LA: The epidemiology of cervical carcinogenesis. Cancer 2006, 76(S10):1888-1901.

doi:10.1186/1471-2458-13-582

Cite this article as: Ononogbu et al: Cervical cancer risk factors among HIV-infected Nigerian women. BMC Public Health 2013 13:582.

\section{Submit your next manuscript to BioMed Central and take full advantage of:}

- Convenient online submission

- Thorough peer review

- No space constraints or color figure charges

- Immediate publication on acceptance

- Inclusion in PubMed, CAS, Scopus and Google Scholar

- Research which is freely available for redistribution 